\title{
Low Friction Sliding Planes of Greased PTFE for High Contact Pressures
}

\author{
Lennart Bocklenberg1, Karsten Winkler², Peter Mark1, Stefan Rybarz² \\ ${ }^{1}$ Institute of Concrete Structures, Ruhr-Universität Bochum, Bochum, Germany \\ ${ }^{2}$ Institute for Structural Engineering, Structural Testing Laboratory (KIB-KON), Ruhr-Universität Bochum, \\ Bochum, Germany \\ Email: Lennart.Bocklenberg@rub.de
}

Received 5 January 2016; accepted 11 March 2016; published 14 March 2016

Copyright (C) 2016 by authors and Scientific Research Publishing Inc.

This work is licensed under the Creative Commons Attribution International License (CC BY). http://creativecommons.org/licenses/by/4.0/

(C) (i) Open Access

\begin{abstract}
Sliding planes of PTFE are commonly used because of their excellent tribological properties. However, especially in cases of high contact pressures, PTFE suffers from its comparatively poor mechanical properties. This paper presents a sliding construction developed within an innovative experimental test-setup to enable experimental investigation of large-scale concrete members subjected to punching shear. To fulfill the special demands of the new test-setup, greased, only 0.5 $\mathrm{mm}$ thin sheets of PTFE were used to minimize friction between the bearing construction and the test specimen. This highly effective sliding construction leads to a dynamic friction coefficient $\mu_{\mathrm{d}, \max }$ between 0.0065 and 0.0035 while the static friction coefficient $\mu_{s}$ remains below 0.0048 . Simultaneously, compressive axial stresses of more than $60 \mathrm{MPa}$ occur. The paper highlights major aspects of the sliding plane's development and demonstrates its sliding abilities.
\end{abstract}

\section{Keywords}

Sliding Plane, PTFE, Innovative Test-Setup, Experiments

\section{Introduction}

Polytetrafluoroethylene (PTFE) is one of the most frequently used solid sliding materials in the world. Due to its unique tribological properties, PTFE is nowadays established in a wide range of applications [1] [2]. Especially its very low friction coefficient, even for high contact pressures up to $90 \mathrm{MPa}$ [3], has made PTFE popular as an engineering material.

However, PTFE exhibits comparatively poor mechanical properties and a high rate of wear. One way to improve the rate of wear and the mechanical properties of PTFE is to incorporate filler materials such as glass fi- 
bers, bronze or carbon. For example, Khedkar, et al. [4] and Conte, et al. [5] showed that fillers considerably increase the hardness and wear-resistance of PTFE-composites. However and in turn, its integration might also impair the tribological properties of PTFE, especially for high contact pressures.

In civil engineering earlier studies of Mark, et al. [6] and Vonk [7] have shown a different way to benefit from the advantageous sliding characteristics of PTFE for high contact pressures. In the framework of experimental investigations of concrete properties they used PTFE to allow a free lateral extension at the loading plates in standard concrete cube tests. Sheets of PTFE were placed between the loading plates and a concrete test member. To account for an essentially lower Young's modulus of PTFE compared to concrete, very thin sheets of PTFE with a thickness of $0.05 \mathrm{~mm}$ were applied (Figure 1(a)). While these thin sheets reduced the influence on their test results successfully, experimental investigations with larger sliding paths revealed instability of the sliding sheets along with a loss of sliding abilities.

Nevertheless, PTFE is also used in case of substantially greater sliding paths. In order to preserve its sliding abilities, the thickness of the PTFE-sheets is then increased. For example, ordinary bridge bearings are equipped with PTFE-sheets of about 3 - $5 \mathrm{~mm}$ thickness (Figure 1(c)) [8]. Consequently and mainly due to the lower Young's modulus of PTFE compared to the steel components of the bearing constructions, substantially greater deformations occur. Such deformations are acceptable for bridge bearings because of relatively small axial stresses. But, in an innovative test-setup for concrete slabs subjected to punching shear currently developed at Ruhr-Universität Bochum in Germany, compressive stresses up to 64 MPa occur [9]-[11]. Here, the rotational rigidity required would no longer be satisfied with thick PTFE-sheets.

In the remainder a sliding construction, fundamental for cost effective punching shear tests of large concrete slabs of practical relevance, is introduced, that complies rotational rigidity as well as sufficient shape stability. The basic concept of this new experimental test-setup is the application of the best practice in numerical investigations. By utilizing symmetry conditions, test loads, physical dimensions and self-weights are drastically reduced. As a result, considerably larger slabs can be tested with existing test infrastructure.

Prerequisite of this concept is the development of a symmetry bearing to fulfill the symmetry conditions at the symmetry lines of a punching test. Therefore, a bearing construction allowing almost frictionless sliding in vertical and horizontal directions as well as a rotational rigidity (almost no deformability) must be established.

Sliding planes of greased PTFE have proven to be suitable in this regard since they show excellent tribological properties even with high compressive axial stresses. Within the development process, PTFE-sheets of 0.5 $\mathrm{mm}$ thickness have proved to be particularly suitable (Figure 1(b)). The purpose of this paper is to highlight the major development steps of this sliding construction as well as to present the sliding abilities achieved.

\section{Experimental Details}

\subsection{Requirements of the Tribological System}

The new experimental test-setup is developed in a step-by-step procedure. Important components like the sliding
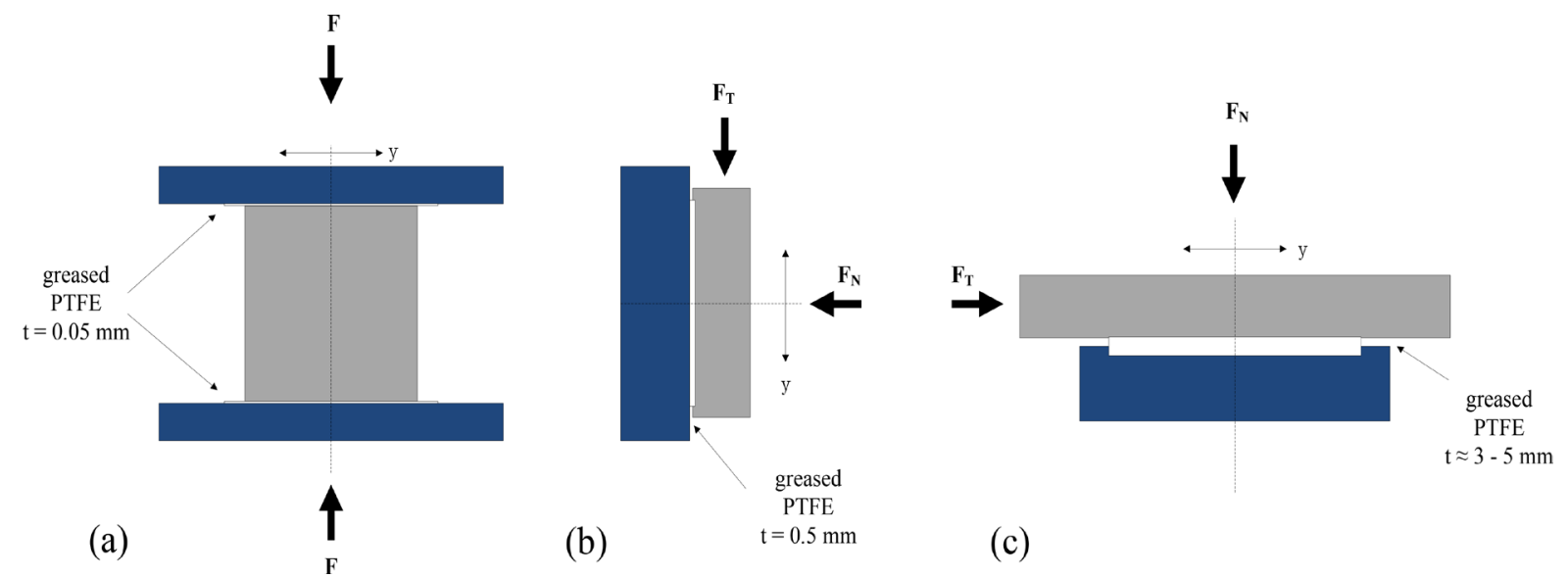

(b)

(c)

Figure 1. Examples of sliding planes (a) standard concrete cube test-setup, (b) own development, (c) sliding bearing for bridges. 
plane or the back anchoring system are developed and optimized separately. To avoid unnecessary factors of influence, the sliding planes are developed strictly without concrete test members. However, certain demands are formulated to ensure the functionality of the sliding plane for subsequent use within the test-setup [10].

The requirements of the tribological system are:

- Unidirectional vertical (up to $30 \mathrm{~mm}$ ) and lateral (a few mm) movements.

- Small friction coefficient (smaller than 1\%) with simultaneous compressive axial stresses of more than 60 MPa.

- Negligible inherent deformability: small rotations between sliding plate and bearing construction, no horizontal movements perpendicular to the bearing construction.

\subsection{Sheets of PTFE}

Polytetrafluoroethylene has a very complex tribological behavior. The relation between compressive axial stresses and the friction coefficient is reciprocal and depends on lots of variables. PTFE exhibits a low friction coefficient when it slides on a hard counter surface, especially stainless steel is commonly used. Additionally, the friction coefficient decreases with falling temperature, with low sliding speed and a low roughness of the counter surface [12].

Due to its chemical composition, PTFE has a strong tendency for creeping and yielding. PTFE (virgin) already starts to yield when the contact pressure reaches approx. $7 \mathrm{MPa}$ [3]. However, confined by chambers, the shape stability of the material can be increased several times compared to the initial level. In this process, the edges of the chambers keep the PTFE in shape. For this purpose the edges of the chambers must not be chamfered but sharp-edged. In addition, the edges and the counter surface must not come into contact with each other [13].

Figure 2(a) shows the technical realization of the chambers for an anchorage plate within the presented testsetup. The sheets of PTFE are placed in the milled chambers with millimeter precision (Figure 2(c)). The milled chambers, $0.3 \mathrm{~mm}$ deep, were added to the anchorage plate by a CNC-machine. Additionally, double-faced adhesive tape is used to keep the PTFE in place until the concrete test member is pre-stressed against the bearing construction (Figure 2(b)).

\subsection{Lubrication and Dimpling}

Both lubricating grease and dimples have advantageous effects on the friction coefficient. It is well-established that the use of lubrication leads to a much lower friction coefficient. In the case of high pressure, however, the lubrication grease is squeezed out of the sliding plane. Consequently, the friction coefficient increases especially for higher slide paths. To prevent this, dimples are arranged to ensure a continuous greasing.
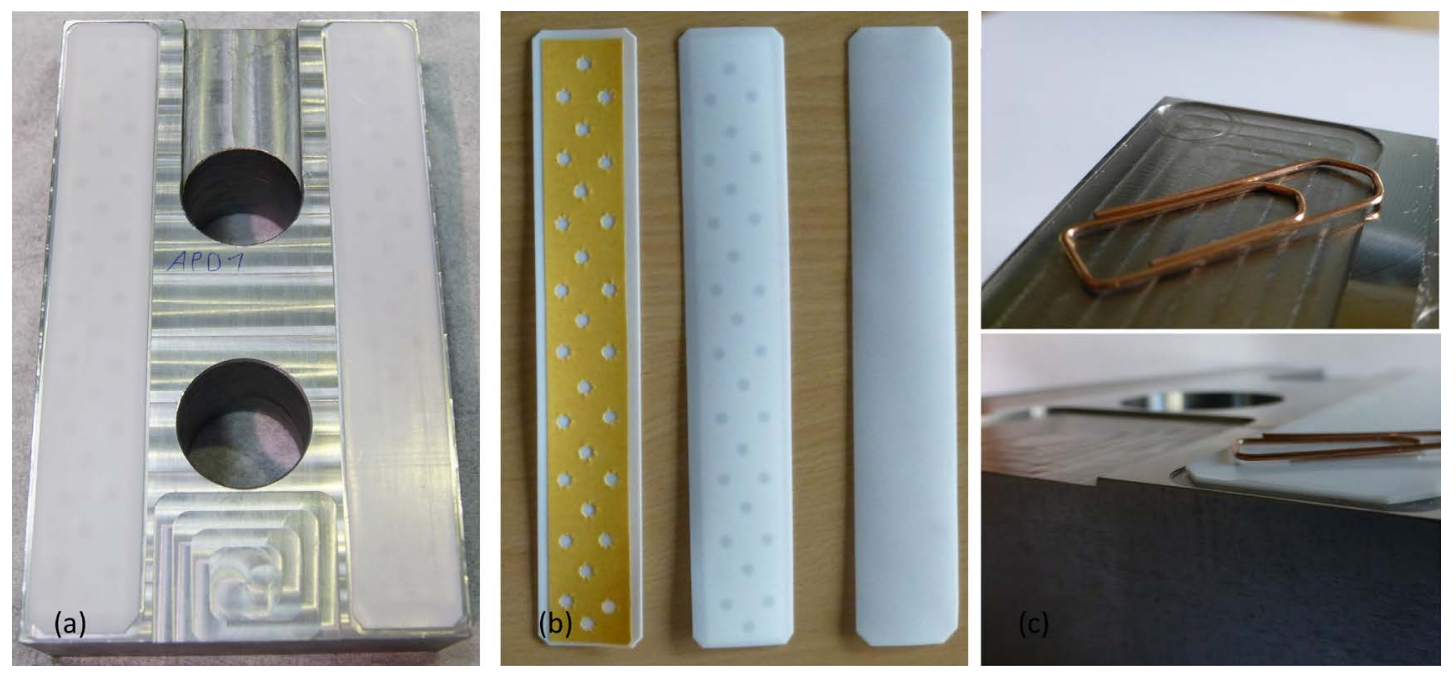

Figure 2. Anchorage plate (a) equipped with two sheets of PTFE, (b) $0.5 \mathrm{~mm}$ thin PTFE-sheets, (c) chambers of sliding plates [9]. 
Usually lubricating grease for PTFE/Stainless Steel connections is based on silicone oil and lithium soap. In the presented work, the lubricating grease Syntheso 8002 is used. This lubricating grease, produced by KLUEBER, has been especially developed for plane bridge bearings [14]. The lubricating grease was uniformly brushed onto all four surfaces of the sliding construction.

With regard to bridge bearings the PTFE-sheets are equipped with dimples to ensure a continuous and uniformly greasing. Figure 3(a) shows a typical distribution of dimples on a structural sliding bearing. Due to limited space, the dimples of the presented sliding plane are arranged on a rectangular grid with 6 respectively 10 $\mathrm{mm}$ increments and a diameter of $4 \mathrm{~mm}$. The layout of the grid is specifically designed, so that the dimples are nearly overlapping in the direction of movement.

In the development process of the sliding plane the very low thickness of the PTFE-sheets posed a special challenge. Initial attempts with perforated PTFE-sheets led to an impairment of the sliding abilities. Much better results are achieved with a perforation of the double-faced adhesive tape. Due to high compressive axial stresses resulting from the pre-stressing process and the low thickness of the PTFE, the lubricating grease and the PTFE are pressed into the perforation. The occurring dimples prevent the lubrication grease of squeezing out.

\subsection{Test-Setup for Performance Tests}

In order to determine the friction coefficient of the sliding construction, performance tests were carried out. The performance tests were conducted at the structural testing laboratory (KIB-KON) of the Ruhr-Universität Bochum. The main characteristics of the tests are summarized in Table 1.

typical structural bearing

PTFE

(a)

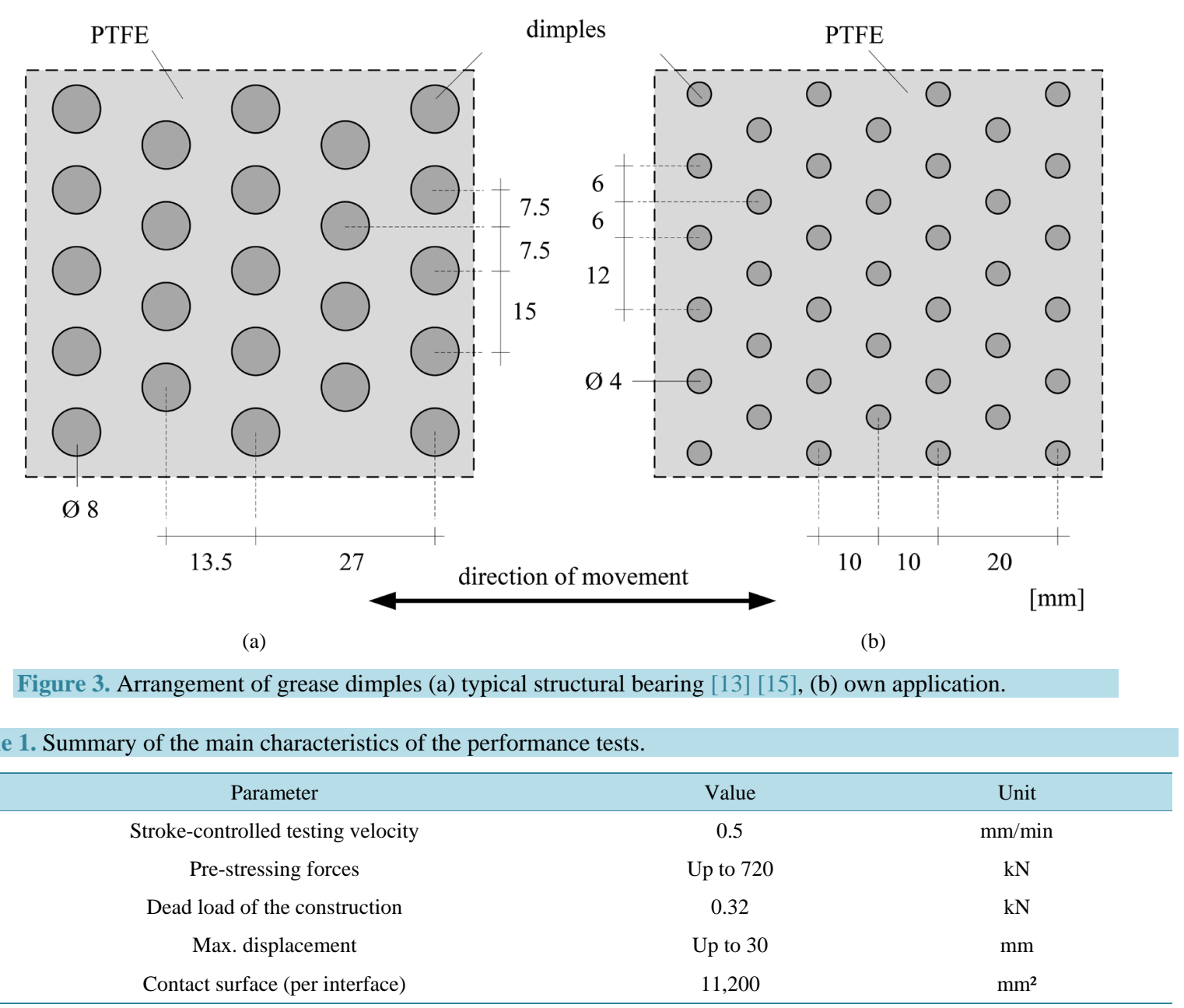

adapted for $0.5 \mathrm{~mm}$ PTFE-sheets 
For the determination of the friction coefficient $\mu$ Equation (1) is used. In this equation the friction coefficient $\mu$ is defined as the ratio of vertical to horizontal loads. The dead load $\mathrm{G}$ of the construction, consisting of anchorage plates, spherical bearings (calottes), screw nuts (M33) and threaded rods (ISO-metric, M33), was determined by measuring the weight of all components before test. The horizontal load $\mathrm{F}_{\mathrm{N}}$ is generated by prestressing the anchorage plates against the bearing construction. $\mathrm{F}_{\mathrm{T}}$, the tangential testing load, is introduced by hydraulic jacks.

$$
\mu=\frac{F_{\mu}}{F_{N}}=\frac{G+F_{T}}{F_{N}}
$$

Figure 4 shows the configuration of the sliding plane for the performance tests on one side. The sliding components consisting of screw nuts, calottes and an anchorage plate are built up at the bearing construction by mounting on the threaded rods. As can be seen from Figure 4, the threaded rod and screw nut at the lower end of the anchorage plate had to be modified due to limited space given at the pre-stressing process. Calottes are also used to reduce slipping effects between screw nuts and threaded rods during pre-stressing.

Figure 5 illustrates the test-setup and measuring equipment for the executed sliding tests. To connect both anchorage plates, threaded rods are used. In between the spacings of the steel frame construction the threaded rods are manufactured with plane surfaces for strain gauge application. The strain gauges are applied to measure elongation of threaded rods and are used to control the pre-stressing force at assembly and during tests. By using hydraulic jacks with a capacity of $700 \mathrm{bar}$, a pre-stressing force up to $720 \mathrm{kN}$ - $360 \mathrm{kN}$ per threaded rod - can be applied. This pre-stressing force in connection with the contact surface leads to maximal compressive axial stresses of approximately $64 \mathrm{MPa}$ in the sliding planes. As additional measuring equipment, four linear displacement transducers (LDTs) are used to record the horizontal $\left(\mathrm{w}_{\mathrm{H} 1}, \mathrm{w}_{\mathrm{H} 2}\right)$ and vertical $\left(\mathrm{w}_{\mathrm{V} 1}, \mathrm{w}_{\mathrm{V} 2}\right)$ displacements at both anchorage plates. The positions of all LDTs as well as their maximum measuring range can be seen in Figure 5(b).

In order to carry out the performance tests, two anchorage plates are prepared as described in section 2 . Before the double-faced adhesive tapes and PTFE-sheets are applied, all essential surfaces are cleaned with industrial cleaner to ensure consistent conditions. Subsequently, the lubrication grease is added generous onto all four surfaces of the sliding plane by distributing it uniformly with a brush. Afterwards, all sliding components are arranged and aligned at the bearing construction as shown in Figure 4. After all components are aligned at the bearing element, the pre-stressing process starts. Starting with the threaded rod at the lower end of the anchorage plate, a pre-stressing force is applied by using a hydraulic jack. The pre-stressing force is applied in 50 bar steps until the required pre-stress force of $700 \mathrm{bar}$ is achieved. With the help of a ring wrench, the screw nuts are tigh-

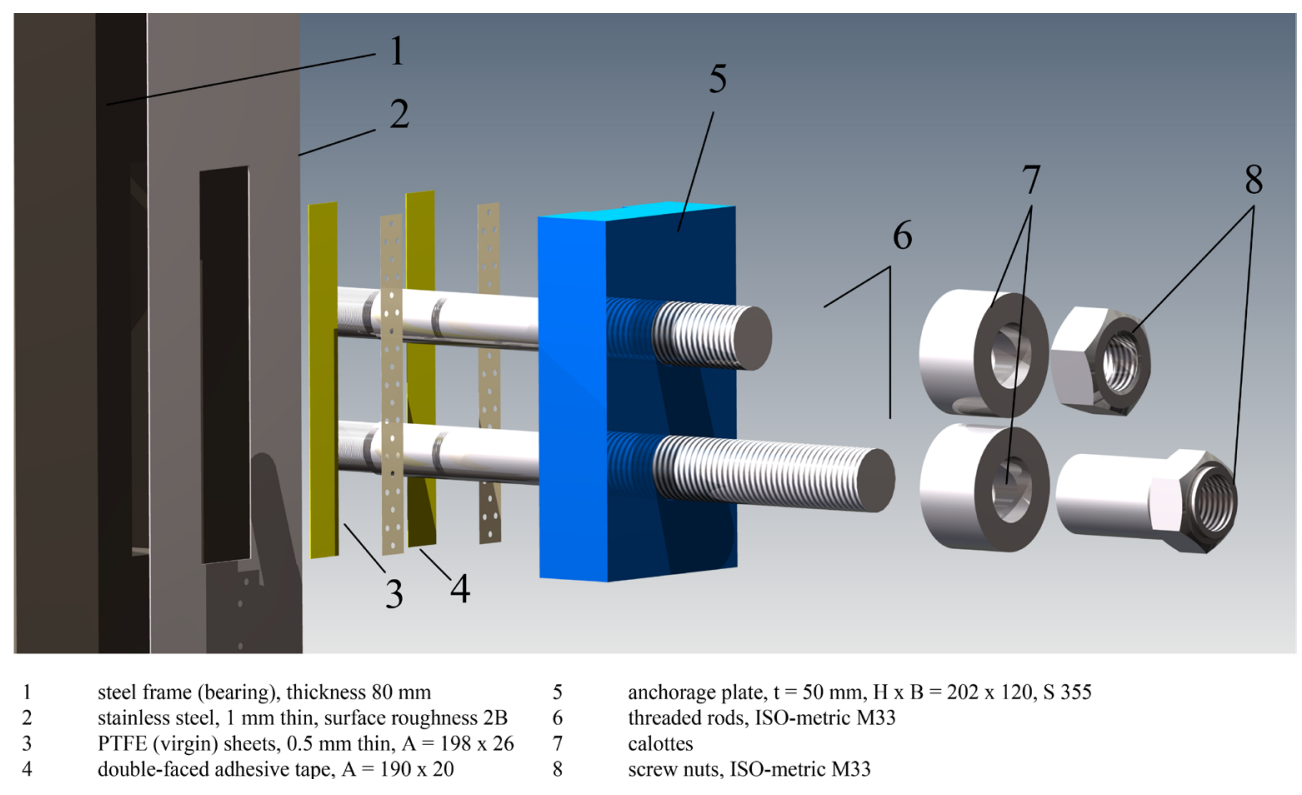

Figure 4. Configuration of the sliding plane (one side). 


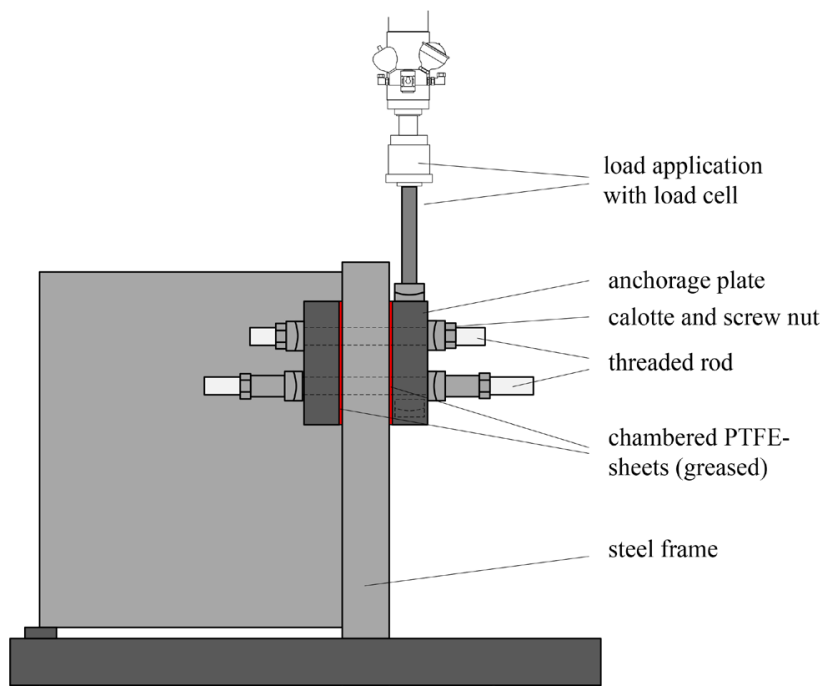

(a)

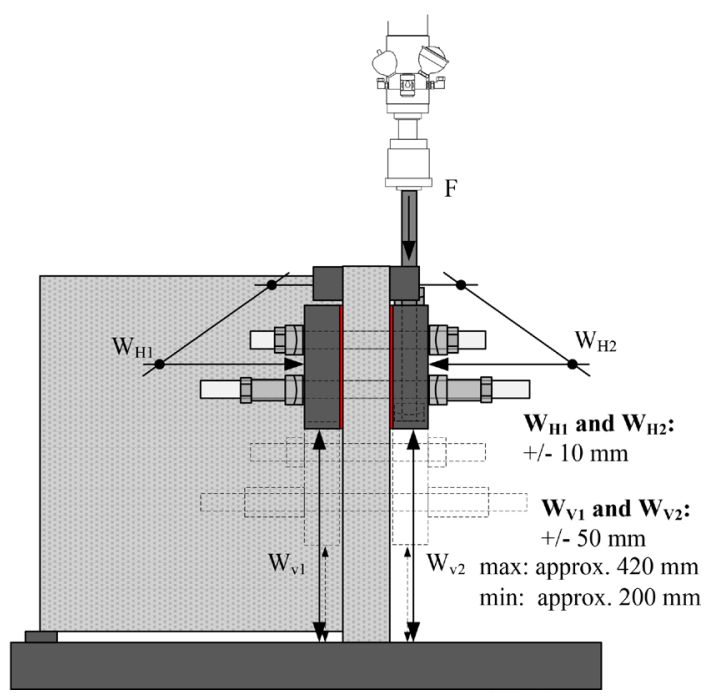

(b)

Figure 5. Test-setup for performance test (a) components of the test-setup, (b) measuring equipment [9].

tened and overstretched by about $+0.3 \%$. The overstretching is performed to compensate losses of the prestressing force due to retracting the hydraulic jack. In order to prevent torsions of the test specimen, the rear anchorage plate is held with a template during the pre-stressing process. After the pre-stressing process of the lower threaded rod has been completed, this procedure is repeated on the threaded rod at the upper end of the anchorage plate. The sequence of the pre-stressing process is chosen with regard to the pre-stressing procedure within the innovative test-setup for punching shear tests on concrete test members.

Subsequent to the pre-stressing process a time interval of exactly 10 minutes is used to set up the measuring equipment and to align the load application at the anchorage plate on the front side of the bearing element (Figure 5). The time interval of 10 minutes is selected to keep the losses of the pre-stressing force comparable. At last, the load application is started in a stroke-controlled way with a constant testing velocity of $0.5 \mathrm{~mm} / \mathrm{min}$. Consequently, one performance test takes approximately 60 minutes.

For the performance tests two symmetry bearing elements (X and $\mathrm{Y}$ ) are available. The elements are made from a $\mathrm{t}=80 \mathrm{~mm}$ steel front plate and six $\mathrm{t}=40 \mathrm{~mm}$ steel panels welded to a comb-shaped construction. To fix the bearing construction, vertical rods are pre-stressed in the concrete floor of the testing laboratory. In Figure 6(a) the bearing element $\mathrm{X}$ equipped for a performance test is shown. At each bearing construction five openings are available. Within the framework of the innovative test-setup for punching shear tests on concrete test members all openings of both bearing constructions are used at the same time. Therefore, the performance tests are conducted on different openings to investigate a potential effect of various positions of the sliding construction on the test results. The notation of the positions for the performance tests can be read from Figure 6(b). It is important to note, that the notation of the positions at the bearing element $\mathrm{Y}$ are mirrored.

\section{Achieved Sliding Abilities}

\subsection{Results of Recent Performance Tests}

To assess the quality of the developed sliding plane an experimental test program with the final configuration of the sliding plane was carried out. Important parameters and main results of the tests are summarized in Table 2. The experimental program included 17 tests with different positions and orientations at the bearing construction. Due to the pre-stressing process and the complex tribological system, the pre-stressing forces varied from test to test. To express these variations the characteristic values $P_{0,(t=0)}, P_{0, m}$ and $P_{0, \min }$ are represented in Table 2 . These variations influence the scatter of the results but cannot be avoided.

The results of the performance tests are presented in Figure 7 and Figure 8 in terms of $\mu$-mm diagrams. Starting from the experimental results of one position at the bearing construction, Figure 7 indicates the test results of position Xa (Table 2). The tests are conducted on two consecutive days under almost identical conditions. In spite of excellent test conditions, the mean pre-stressing force $\mathrm{P}_{0, \mathrm{~m}}$ varies by approx. $50 \mathrm{kN}$. Neverthe- 


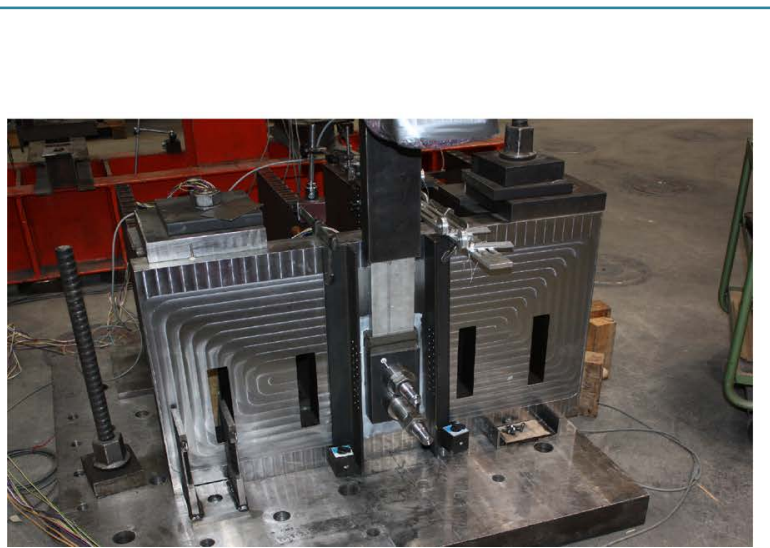

(a)

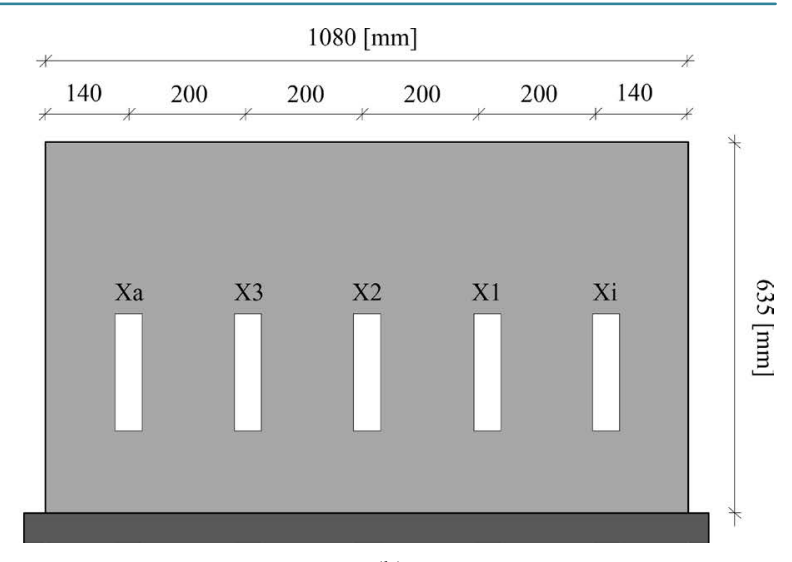

(b)

Figure 6. Symmetry bearing (a) equipped for a performance test [10], (b) notation of the openings at the bearing construction X.

Table 2. Summary of important parameters and experimental results of performance tests [9].

\begin{tabular}{|c|c|c|c|c|c|c|c|c|c|}
\hline \multirow{2}{*}{ Name } & \multirow{2}{*}{ Position } & \multirow{2}{*}{ Orientation } & $\mathrm{P}_{0,(\mathrm{t}=0)}$ & $\mathrm{P}_{0, \mathrm{~m}}$ & $\mathrm{P}_{0, \text { min }}$ & $\mu_{\mathrm{s}}$ & $\mu_{\mathrm{d}, \max }$ & $\mathrm{F}_{\mathrm{s}, \max }$ & $\mathrm{F}_{\mathrm{d}, \max }$ \\
\hline & & & {$[\mathrm{kN}]$} & {$[\mathrm{kN}]$} & {$[\mathrm{kN}]$} & {$[\%]$} & [\%] & {$[\mathrm{kN}]$} & {$[\mathrm{kN}]$} \\
\hline GRV-Xi-20140612 & $\mathrm{Xi}$ & Punching shear & 650 & 644 & 640 & 0.43 & 0.41 & 2.48 & 2.32 \\
\hline GRV-X1-20130605 & $\mathrm{X} 1$ & Punching shear & 652 & 642 & 634 & 0.43 & 0.53 & 2.48 & 3.08 \\
\hline GRV-X2-20140605 & $\mathrm{X} 2$ & Punching shear & 655 & 648 & 643 & 0.38 & 0.41 & 2.17 & 2.34 \\
\hline GRV-X3-20140604 & $\mathrm{X} 3$ & Punching shear & 646 & 625 & 633 & 0.26 & 0.46 & 1.36 & 2.56 \\
\hline GRV-Xa-20140604 & $\mathrm{Xa}$ & Punching shear & 656 & 647 & 640 & 0.42 & 0.41 & 2.44 & 2.33 \\
\hline GRV-2014-1-Xa-inverted & Xа & Inverted & 696 & 689 & 685 & 0.48 & 0.42 & 3.02 & 2.57 \\
\hline GRV-2014-2-Xa-inverted & Ха & Inverted & 708 & 697 & 693 & 0.37 & 0.35 & 2.30 & 2.12 \\
\hline GRV-2014-3-Xa-inverted & $\mathrm{Xa}$ & Inverted & 700 & 640 & 599 & 0.37 & 0.52 & 2.27 & 3.01 \\
\hline GRV-2014-4-Xa-inverted & Ха & Inverted & 688 & 682 & 679 & 0.39 & 0.40 & 2.36 & 2.41 \\
\hline GRV-Yi-20140523 & Yi & Punching shear & 695 & 649 & 609 & 0.10 & 0.58 & 0.38 & 3.44 \\
\hline GRV-Yi-II-20140603 & $\mathrm{Yi}$ & Punching shear & 602 & 553 & 510 & 0.08 & 0.50 & 0.16 & 2.45 \\
\hline GRV-Y1-20140526 & Y1 & Punching shear & 640 & 602 & 569 & 0.20 & 0.65 & 0.96 & 3.59 \\
\hline GRV-Y1-II-20140526 & Y1 & Punching shear & 615 & 580 & 549 & 0.30 & 0.39 & 1.53 & 1.94 \\
\hline GRV-Y2-20140522 & $\mathrm{Y} 2$ & Punching shear & 620 & 596 & 576 & 0.17 & 0.37 & 0.73 & 1.89 \\
\hline GRV-Y2-II-20140527 & $\mathrm{Y} 2$ & Punching shear & 664 & 639 & 618 & 0.13 & 0.42 & 0.54 & 2.36 \\
\hline GRV-Y3-II-20140528 & Y3 & Punching shear & 658 & 632 & 612 & 0.28 & 0.59 & 1.52 & 3.41 \\
\hline GRV-Ya-II-20140602 & Ya & Punching shear & 651 & 625 & 609 & 0.22 & 0.57 & 1.11 & 3.24 \\
\hline
\end{tabular}

$\mathrm{P}_{0,(\mathrm{t}=0)}=$ initial pre-stressing force; $\mathrm{P}_{0, \mathrm{~m}}=$ mean pre-stressing force; $\mathrm{P}_{0, \text { min }}=$ minimal pre-stressing force; $\mu_{\mathrm{s}}=$ coefficient of static friction; $\mu_{\mathrm{d}}=$ coefficient of dynamic friction; $\mathrm{F}_{\mathrm{s}}=$ tangential test load corresponding to $\mu_{\mathrm{s}} ; \mathrm{F}_{\mathrm{d} \text {,max }}=$ tangential test load corresponding to $\mu_{\mathrm{d} \text {,max }}$.

less, the values of the coefficient of static friction $\mu_{\mathrm{s}}$ ranges between $0.37 \%$ and $0.48 \%$ and the coefficient of dynamic friction $\mu_{\mathrm{d} \text {,max }}$ varies from $0.26 \%$ to $0.52 \%$ (Figure $7(\mathrm{a})$ ). Additionally, a comparison of the curve progression indicates that the friction coefficient tend to remain nearly steady over the sliding distance of about $30 \mathrm{~mm}$.

Figure 7(b) shows the corresponding tangential test load $\mathrm{F}_{\mathrm{T}}$ without the dead load $\mathrm{G}$ of the construction. Despite the very high compressive axial stresses of more than $60 \mathrm{MPa}$, a maximum force of only $3 \mathrm{kN}$ is necessary to set the construction in motion and to keep that motion going.

Figure 8 shows a compilation of all test results summarized in Table 2. Based on the larger number of performance tests, the variance of the results increases. However, a minimal dependence of the friction coefficient and the particular frame position was observed. In spite of this dependence, all test results show negligible small variations of the friction coefficient over the sliding distance. Comparing all results, it can be seen, that the maximum friction coefficient of $0.65 \%$ is substantially below $1 \%$, the requirement of the new test-setup. It 


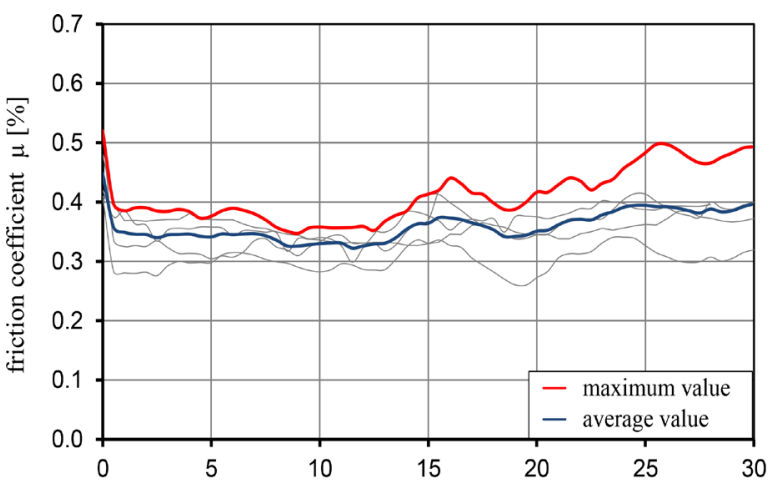

(a)

distance of sliding [mm]

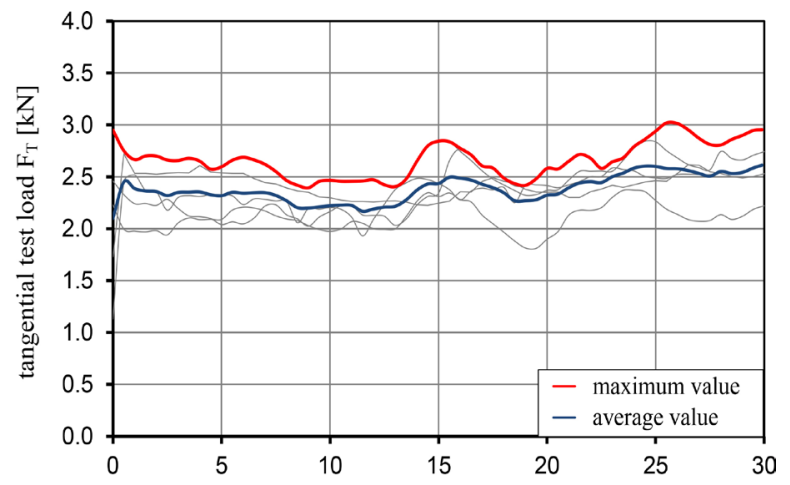

(b)

distance of sliding [mm]

Figure 7. Performance test results at position Xa (a) relation between friction coefficient and distance of sliding, (b) relation between tangential test load and distance of sliding [9].

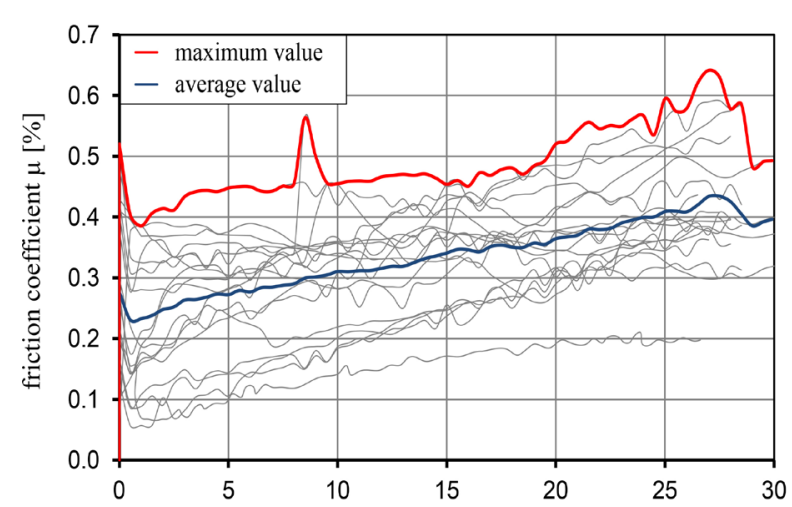

(a)

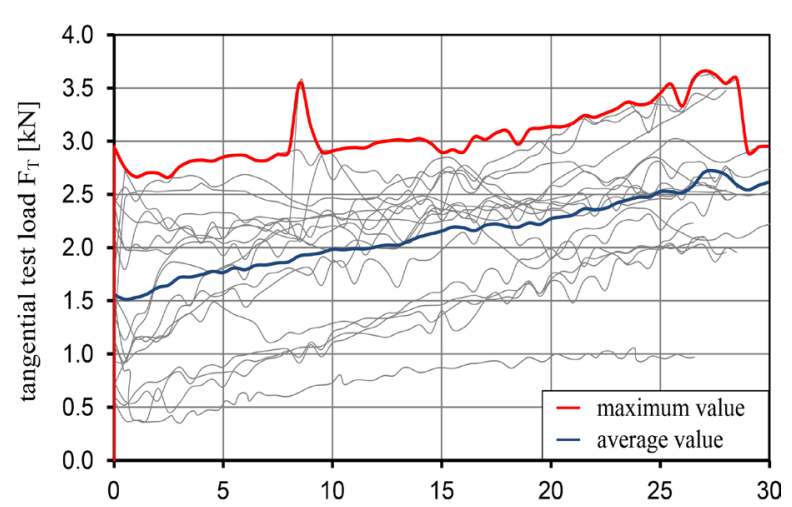

(b)

distance of sliding $[\mathrm{mm}]$

Figure 8. Comparison of all test results (a) relation between friction coefficient and distance of sliding, (b) relation between tangential test load and distance of sliding [9].

should be mentioned that larger friction coefficients usually are a result of instabilities of the sliding sheets caused by alignment at the openings of the steel bearing or imprecise assembly.

\subsection{Stop-and-Go Test}

In addition to the performance tests a stop-and-go test was carried out to investigate the influence of a notuniformly movement of a test member (stick and slip effect). The stop-and-go test was performed with the test member GRV-2014-4-Xa-inverted (Table 2) and started subsequently to its performance test. Compared with the performance tests, only the load pattern has changed, all other parameters remain constant.

Figure 9(b) indicates the scheduled testing velocity over the time. After a first stage of loading (5 minutes), ten load cycles with 30 seconds stops and 1 minute load phases each are conducted. During the last load phase of the test program, the testing velocity remains constant for another 10 minutes. Consequently, the complete test program takes 29 minutes. It is important to note that in the 30 seconds stop phases the stroke controlled test is maintained at a constant level and is not relieved. However, at the last cycle the test member was relieved to investigate the effect on the sliding behavior (Figure 9(a)).

In Figure 9(a), the test results of the stop-and-go test are shown. Despite multiple changes from static friction to dynamic friction, the friction coefficient remains always below $0.5 \%$. Even with a cumulated sliding distance of about $42 \mathrm{~mm}$ (30 mm performance test and approx. $12 \mathrm{~mm}$ stop-and-go test) the friction coefficient indicates a constant progression. It should be mentioned that the sliding distance in Figure 9(a) was monitored by the $\mathrm{LDT}_{\mathrm{v} 2}$ (Figure 5(b)). Thus, the load pattern and the measured sliding distance do not match exactly. Moreover, the last decrease of the friction coefficient at approx. $7.2 \mathrm{~mm}$ was not caused by the load pattern and remained unclear. 


\subsection{Coupling of Sliding Planes}

Figure 10 presents the final sliding plane ready for application within the new experimental test-setup. The illustrated concrete test member is equipped with six coupled sliding plates in two symmetry lines. Figure 10(a) shows the test member along with the sliding plates before the test-setup is assembled. Two orthogonally arranged steel frames, similar to the steel frame in the performance tests, are used as bearing construction. To enable the pre-stressing process, six anchorage plates are added on the rear side of the bearing construction. The dimples, due to the perforated double-faced adhesive tape, are clearly recognizable after test (Figure 10(b)).

To evaluate the functionality of the coupled system, a matching monitoring concept was elaborated. In order to determine the friction coefficient according to Equation (1), the test load, the vertical reaction force (globally) as well as the vertical displacement and the pre-stressing force of all six sliding elements (locally) are measured (Figure 11(b)). In contrast to the performance tests, the friction force $\mathrm{F}_{\mu}$ can be calculated from the difference between the tangential test load $\mathrm{F}_{\mathrm{T}}$ and the reaction force $\mathrm{F}_{\mathrm{A}}$. The pre-stressing forces are derived from $2 \times 2 \times 6=$ 24 strain gauges applied at 12 threaded rods, equivalently to the performance tests.

Figure 11(a) indicates the experimental response of the test member. The tangential test load $\mathrm{F}_{\mathrm{T}}$, the reaction force $\mathrm{F}_{\mathrm{A}}$ and the friction force $\mathrm{F}_{\mu}$ are plotted versus the vertical displacement of the test cylinder. It can be seen that the friction force $\mathrm{F}_{\mu}$ remains almost constant over the deformation paths after exceeding the point of static friction at $\mathrm{F}_{\mathrm{T}} \approx 18 \mathrm{kN}$. Even the failure at $\mathrm{F}_{\mathrm{T}} \approx 89 \mathrm{kN}$ and the following load-deflection behavior is well reproduced.

An exact calculation of the friction coefficient similar to the performance tests is unfeasible due to the fact, that each sliding plate exhibits different vertical displacements and pre-stressing forces. Nevertheless and in order to be able to assess the quality of the sliding system, an average friction coefficient is calculated. The calculation is based on the following values:
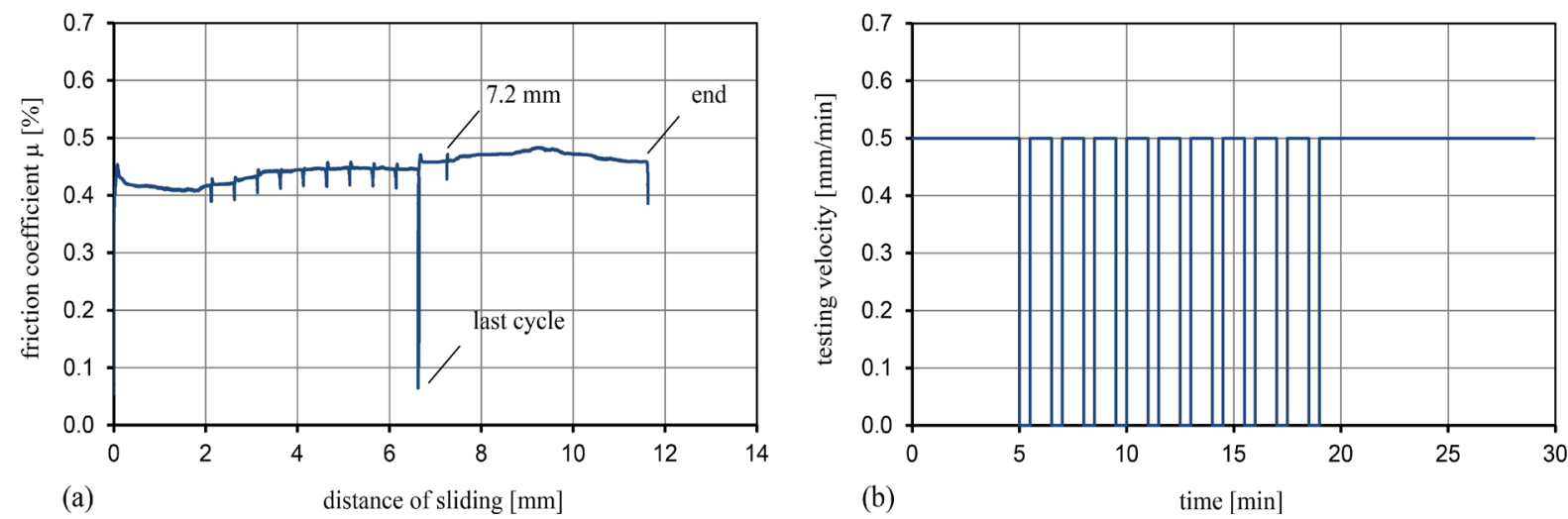

(a)

distance of sliding $[\mathrm{mm}]$

time $[\mathrm{min}]$

Figure 9. Stop-and-go test (a) relation between friction coefficient and distance of sliding, (b) load pattern.


Figure 10. Test-setup with coupled sliding plates (a) concrete test member with sliding plate, (b) anchorage plate equipped with two PTFE-sheets after tests. 
- Average pre-stressing force when exceeding the point of static friction (separately for each sliding plate).

- Maximal difference between the tangential test load $\mathrm{F}_{\mathrm{T}}$ and the reaction force $\mathrm{F}_{\mathrm{A}}$ when exceeding the point of static friction (uniformly distributed over all sliding plates).

- Maximal vertical displacement of each sliding plate until failure occurs.

It is important to note that an analysis of the LDTs (Figure 11(b)) revealed that all sliding plates start to move simultaneously. This confirms the assumption that the tangential test load $\mathrm{F}_{\mathrm{T}}$ can be uniformly distributed over all sliding plates.

Figure 12 shows the results of the calculations. In accordance with the performance tests, the calculated average friction coefficient $\mu$ of the coupled sliding plates ranges between $0.38 \%$ and $0.42 \%$. Simultaneously, the



(a)
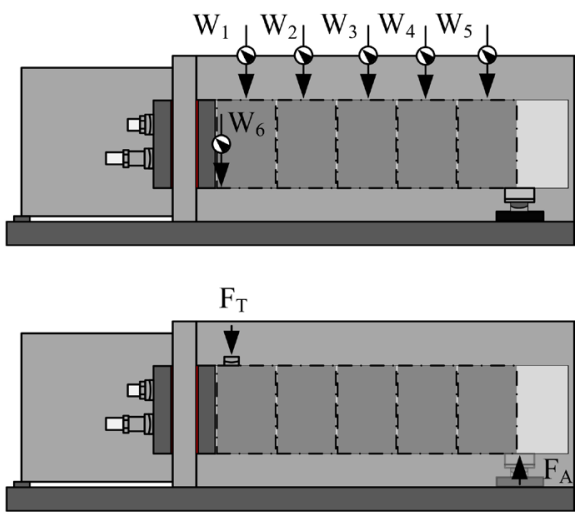

(b)

Figure 11. Test-setup with coupled sliding plates (a) experimental response, (b) monitoring concept.

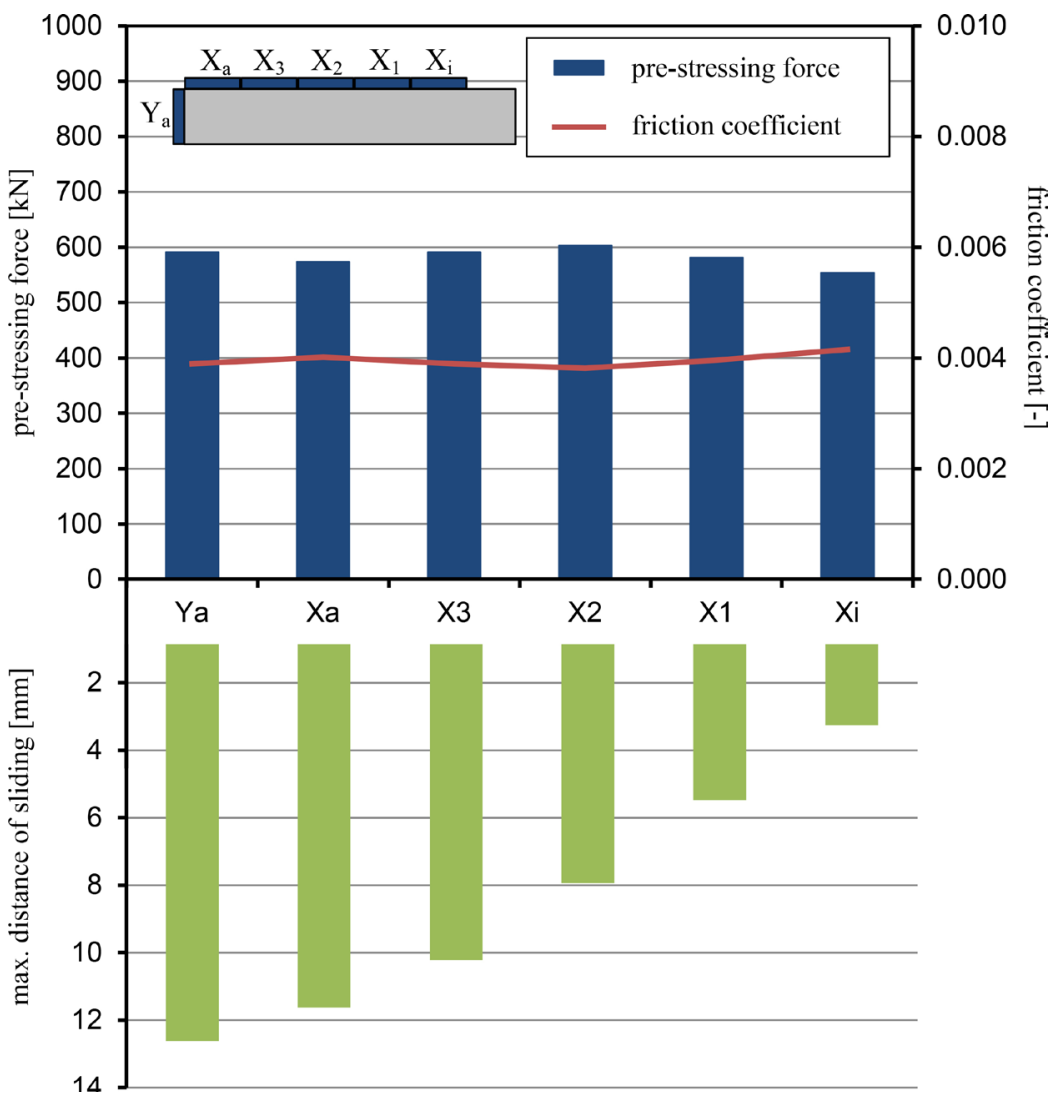

Figure 12. Calculated average friction coefficient of six coupled sliding plates. 
average pre-stressing force differs between 550 to $600 \mathrm{kN}$. A maximum sliding distance of $12.61 \mathrm{~mm}$ occurs. Based on the assumptions to calculate the friction coefficient, the results of the performance tests can be verified for the coupled sliding system. Moreover, all requirements of the tribological system (Section 2.1) are being fulfilled.

\section{Conclusions}

In this paper, a highly effective sliding plane of greased PTFE is presented. The sliding plane was developed within a new experimental test-setup to investigate the punching shear behavior of reinforced concrete slabs utilizing symmetry conditions. Due to the special requirements regarding the bearing construction, an innovative sliding construction had to be developed. As a result of the development process, a deformation resistant sliding plane is obtained that works highly effective even under high compressive axial stresses.

To assess the quality of the developed sliding plane, an experimental test program was carried out. The results of the test program show that the developed sliding plane exceeds the requirements to ensure the functionality of the sliding plane within the new test-setup. Based on the test results, the following conclusions can be drawn:

- The presented sliding plane leads to a friction coefficient $\mu$ below 0.0065 with simultaneous compressive axial stresses of more than $60 \mathrm{MPa}$.

- The friction coefficient $\mu$ tends to remain nearly constant over the sliding distance of about $30 \mathrm{~mm}$.

- Due to the low thickness of the PTFE-sheets, a negligible inherent deformability is achieved.

- A not-uniformly movement of a test member has a negligible influence on the friction coefficient.

- Tests with six coupled sliding plates lead to the conclusion, that the excellent sliding abilities can also be achieved by coupled sliding systems.

\section{Acknowledgements}

The financial support of the research project "Size-dependent punching shear failure of thick reinforced concrete slabs" by the German Research Foundation (DFG) is gratefully acknowledged. The authors like to express their gratitude to the staff of the structural testing laboratory of the Ruhr-Universität Bochum

(http://www.rub.de/kib-kon) involved in this project.

\section{References}

[1] Dominghaus, H., Elsner, P., Eyerer, P. and Hirth, T. (2008) Kunststoffe: Eigenschaften und Anwendungen. 7th Edition, Springer, Berlin Heidelberg New York. http://dx.doi.org/10.1007/978-3-540-72401-8

[2] Kaiser, W. (2007) Kunststoffchemie für Ingenieure, 2nd Edition, Hanser, München. http://dx.doi.org/10.3139/9783446415829

[3] Braun, C., Hanswille, G., Porsch, M. and Schürmann, C. (2009) Structural Bearings for Bridges and Buildings Accordingto DIN EN 1337 (in German: Lager im Bauwesen nach DIN EN 1337). Stahlbau, 78, 849-868. http://dx.doi.org/10.1002/stab.200910101

[4] Khedkar, J., Negulescu, I. and Meletis, E.I. (2002) Sliding Wear Behavior of PTFE Composites. Wear, 225, $361-369$. http://dx.doi.org/10.1016/S0043-1648(01)00859-6

[5] Conte, M. and Igartua, A. (2012) Study of PTFE Composites Tribological Behavior. Wear, 296, 568-574. http://dx.doi.org/10.1016/j.wear.2012.08.015

[6] Mark, P. And Schnütgen, B. (2001) Limits ofElasticMaterial BehaviourofConcrete (in German: Grenzen Elastischen Materialverhaltens von Beton). Beton- und Stahlbetonbau, 96, 373-378. http://dx.doi.org/10.1002/best.200100400

[7] Vonk, R.A. (1993) A Micromechanical Investigation of Softening of Concrete Loaded in Compression. Heron, 38, 394.

[8] Poly Fluoro Ltd. (2015) PTFE Structural Bearings. Brochure. http://www.polyfluoroltd.com/pdf/PFL\%20Bridge\%20Bearings\%20Brochure.pdf

[9] Winkler, K. (2015) Utilizing Symmetry in the Experiment: Bending, Shear and Punching Shear Failure of Reinforced Concrete Beams and Slabs. Ph.D. Thesis, Institute of Concrete Structures, Ruhr-Universität Bochum, Bochum, (Unpublished; in Preparation).

[10] Winkler, K., Mark, P., Heek, P., Rohländer, S. and Sommer, S. (2014) Punching Shear Tests on Symmetrically Reduced Slab Quarters. Structural Concrete, 15, 484-496. http://dx.doi.org/10.1002/suco.201400022

[11] Winkler, K. and Mark, P. (2013) Experimental Realization of SymmetryBearings (in German: Experimentelle 
Umsetzung von Symmetrielagerungen). Beton- und Stahlbetonbau, 108, 47-57. http://dx.doi.org/10.1002/best.201200060

[12] Campbell, T.I. and Kong, W.L. (1989) Laboratory Study of Friction in TFE Sliding Surfaces for Bridge Bearings. Report Nr. MAT-89-04, Research and Development Branch, Ministry of Transportation, Washington DC.

[13] Block, T., Eggert, H. and Kauschke, W. (2013) Lager im Bauwesen, 3rd Edition, Ernst \& Sohn, Berlin, Germany.

[14] Lubrication Grease Syntheso 8002 (Klueber Lubrication). Product Details. http://www.klueber.com/en/product-detail/id/1101/

[15] DIN EN 1337-2:2004 Structural Bearings_-Part 2: Sliding Elements. German Version, Beuth Verlag, Berlin. 